DOC.

D101.60/2:

1770

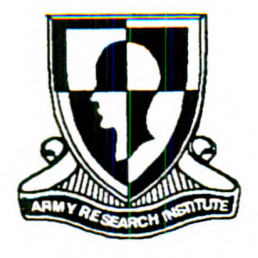

U.S. Army Research Institute

for the Behavioral and Social Sciences

Research Report 1770

\title{
Measures of Platoon Leader Situation Awareness in Virtual Decision-Making Exercises
}

\author{
Laura D. Strater and Mica R. Endsley \\ SA Technologies \\ Robert J. Pleban \\ U.S. Army Research Institute \\ Michael D. Matthews \\ U.S. Military Academy
}

April 2001
MS Cinvt. Document
ienository
Approved for public release; distribution is unlimited.
ARK 012005

